\title{
Presenteeism, Psychosocial Working Conditions and Work Ability among Care Workers-A Cross-Sectional Swedish Population-Based Study
}

\author{
Klas Gustafsson ${ }^{1}{ }^{*}$, Staffan Marklund ${ }^{1}$, Constanze Leineweber ${ }^{2}$, Gunnar Bergström ${ }^{3,4}{ }^{\circledR}$, \\ Emmanuel Aboagye $^{3,4}$ and Magnus Helgesson ${ }^{1}$ \\ 1 Department of Clinical Neuroscience, Division of Insurance Medicine, Karolinska Institutet, \\ SE-171 77 Stockholm, Sweden; staffan.marklund@ki.se (S.M.); magnus.helgesson@ki.se (M.H.) \\ 2 Stress Research Institute, Stockholm University, SE-171 77 Stockholm, Sweden; constanze.leineweber@su.se \\ 3 Department of Occupational Health Sciences and Psychology, Faculty of Health and Occupational Studies, \\ Centre for Musculoskeletal Research, University of Gävle, SE-801 76 Gävle, Sweden; \\ gunnar.bergstrom@hig.se (G.B.); emmanuel.aboagye@hig.se (E.A.) \\ 4 Institute of Environmental Medicine, Unit of Intervention and Implementation Research for Worker Health, \\ Karolinska Institutet, SE-171 77 Stockholm, Sweden \\ * Correspondence: klas.gustafsson@ki.se; Tel.: +46-8-5248-3232
}

Received: 13 March 2020; Accepted: 31 March 2020; Published: 2 April 2020

\begin{abstract}
Presenteeism, attending work while ill, has been examined in different contexts in the last few decades. The aim was to examine whether poor psychosocial working conditions and perceived work ability are associated with increased odds ratios for presenteeism, focusing on nursing professionals and care assistants. A cross-sectional population-based study was conducted. The selected individuals were extracted from representative samples of employees, aged 16-64, who participated in the Swedish Work Environment Surveys between 2001 and 2013 ( $n=$ 45,098). Three dimensions of psychosocial working conditions were measured: job demands, job control, and job support. Presenteeism and perceived work ability was measured. Using multiple logistic regression analyses, odds ratios for presenteeism with $95 \%$ confidence intervals (CI) were estimated. While nurses $(n=1716)$ showed the same presenteeism level as all the other occupation groups $(n=37,125)$, it was more common among care assistants $(n=6257)$. The odds ratio for presenteeism among those with high job demands (OR $=2.37,95 \%$ CI 2.21-2.53), were higher among women than among men. For nursing professionals and care assistants, the odds ratios for presenteeism were highest among those with the lowest work ability level. The problems of presenteeism and low work ability among many health and care workers may be lessened by a reduction in psychosocial demands.
\end{abstract}

Keywords: presenteeism; psychosocial working conditions; nurses; care workers; health; work ability

\section{Introduction}

Sickness presenteeism, attending work while ill, has increased during the last few decades $[1,2]$, especially among nurses and care assistants [3-5] and other healthcare employees [6-8].

A recent systematic review showed that a wide variety of explanatory factors contribute to the prevalence of presenteeism, including psychosocial working conditions, employment conditions, and factors related to sickness insurance [9]. According to a Dutch study, there is an indication that job demands and burnout exhibited a substantial longitudinal relationship with presenteeism among nurses [10]. 
When it comes to sex-related differences in presenteeism, previous studies have provided inconsistent results. Some studies indicated that women report a higher prevalence of presenteeism than men $[2,3,11,12]$, while other studies showed no sex differences [5,13].

Previous research has shown that presenteeism may affect future health negatively $[9,10]$. A higher incidence of presenteeism among nurses may therefore lead to more negative health consequences, which in the long run could result in negative consequences for health organisations and patients [14]. Working while ill may result in low work ability, inefficient work, and an increase in errors, which may lead to productivity loss and, in the case of healthcare personnel, to lower medical safety for patients [15-17]. The costs of presenteeism have been examined in different healthcare contexts, with the findings indicating that presenteeism can adversely affect the quality of patient care and negatively affect patient safety [18], worsen the spread of infectious diseases [19], and delay patient healing [1]. Moreover, Finnish studies have found presenteeism to reduce nurses' work ability [20] and showed that perceived work ability among employees in a food factory may be a robust indicator for assessing perceived productivity loss [21].

The objective of the present study was to examine the extent to which psychosocial working conditions are associated with increased odds ratio of presenteeism, focusing on two occupational groups, nursing professionals and care assistants, and sex-related differences. A specific aim was to examine how perceived work ability was related to presenteeism.

\section{Methods}

\subsection{Ethic Aspects}

The research protocol was approved by the Regional Research Ethics Committee of Stockholm, Sweden in 2015 and 2018 (No: 2015/2203-31/5, No. 2018/223-31/5 and No: 2018/5:2). Other researchers may obtain the same data in the same manner as we did from Statistics Sweden, URL: http://www.scb.se/.

\subsection{Study Design and Participants}

A cross-sectional study based on seven surveys of the working population in Sweden between 2001 and 2013 was conducted. Data were obtained from the Swedish Work Environment Surveys (SWES), conducted every second year since 1989 by Statistics Sweden (SCB) on behalf of the Swedish Work Environment Authority [22]. SWES participants were sampled from the Labor Force Surveys (LFS) conducted by Statistics Sweden. Persons who were asked to respond to the LFSwere randomly selected from the entire Swedish population, stratified by county, sex, citizenship, and employment status. Randomly selected respondents to the LFS, who were gainfully employed and between 16 and 64 years old, were first contacted by telephone; those willing to participate then received a self-completion questionnaire and these respondents constituted the SWES subsample. The current study was based on data from 45,098 working men and women who participated in any biannual wave of the SWES between 2001 and 2013. The participants from the SWES were added to the cohort, and the period for each sub cohort started the year after the interview on January 1st (2001-2013). The annual response rates varied between $77 \%$ and $66 \%$ [22].

\subsection{Measurements}

\subsubsection{Classification of Occupations}

The occupations included in the present study, classified according to the 1996 Swedish Standard Classification of Occupations (SSYK96), were organized into two groups: (1) nursing and midwifery professionals and nursing associate professionals (SSYK 223 and 323; $n=1716$ ), and (2) personal care and related workers (SSYK 513; $n=6257$ ) (www.scb.se, Swedish Standard Classification of Occupations). The first occupational group, "nursing professionals," consists of specialized and non-specialized registered nurses with a university degree working in hospitals and other healthcare organizations. 
The second, labeled "care assistants," consists of personal care and related workers, including assistant nurses, hospital ward assistants, and home-based personal care workers and assistants in childcare. The required educational level for these occupations is generally secondary school level. All of the other occupations in the SWES $(n=37,125)$ were also included and served as a comparison group.

\subsubsection{Presenteeism}

Data on presenteeism were obtained from the SWES, 2001-2013 [22]. The following item was chosen to indicate presenteeism [3,5,10]: "How many times during the past 12 months have you worked, even though you really should have not worked given your medical condition?" The items were answered on a four-point response scale: never $(n=13,395 ; 30 \%)$, once $(n=9362 ; 21 \%)$, two or three times $(n=14,454 ; 32 \%)$, and four times or more $(n=7600 ; 17 \%)$ as well as missing responses ( $n=287 ; 1 \%)$. The responses were dichotomized for analysis into 'no presenteeism' ('never' or 'once') ( $n=22,757 ; 51 \%)$ and 'presenteeism ('two or three times' or 'four times or more') ( $n=22,054 ; 49 \%)$.

\subsubsection{Psychosocial Working Conditions}

Data on psychosocial working conditions were obtained from the SWES [22]. Aspects of working conditions, which were included in the study, covered job demands, job control, and job support.

Job demands and job control were measured by a number of items which served as proxy indicators applicable to the demand-control model [23] as formulated by Karasek and collaborators [24]. Job support from supervisors and from colleagues was each measured by one item. More detailed information on the psychosocial items, the response alternatives, and the coding can be found in a previous publication by the research team [25].

Job demands were captured by the following four items:

- 'Is your work so stressful that you do not have time to talk or even think about something other than work?'

- 'Does your work require your full attention and concentration?'

- 'Do you have so much work that you have to miss lunch, work late or take work home?'

- 'I have far too much to do at work?'

Job control was measured by four items capturing aspects of work pace and work content:

- 'Do you have the opportunity to determine your work pace?'

- 'Are you able to determine when various working duties are to be carried out (for example, by choosing to work a bit faster on some days and taking it easier on other days)?'

- 'Do you participate in decisions on the arrangement of your work (e.g., what is to be done, how to do it or who will work with you)?'

- 'I have too little influence at work?'

Two items captured job support from supervisors and colleagues:

- 'Are you able to get support and encouragement from supervisors, when work feels difficult?'

- 'Are you able to get support and encouragement from colleagues, when work feels difficult?'

All response scales were dichotomized closest to the upper quartile to indicate the most adverse conditions. For the item concerning whether their work required attention and concentration, almost half of the responses were in the 'no' coded category, and it was therefore not possible to use the upper quartile as the cut-off point. Those who answered 'no' on the items comprised the reference group for the analyses.

\subsubsection{Work Ability}

The following item was chosen as an indicator of work ability [22]: 
"We assume that your ability to work, when it was best, is valued at 10 points. How many points would you give your current ability to work? (Please check the appropriate number (1-10 points), 10 points means that your ability to work is at its best right now)." Responses were originally given on a ten-point scale and later coded into five categories, where 1-6 points was seen to indicate low work ability, 7,8 , and 9 points were reported as the original scale, and 10 points was seen to indicate high work ability. The reason for collapsing categories 1-6 into one category was that only $5.2 \%$ of the study population reported these low values. Since this item is only available from 2007 onwards, a reduced sample was used for the analyses including work ability (subsample, $n=24,902$ ).

\subsection{Potential Confounders}

\subsubsection{Sociodemographic Factors}

Sex, age at interview (16-29, 30-39, 40-49, and 50-64 years), education ( $\leq 9$ years, 10-12 years, $>12$ years), country of birth (born in Sweden or other country), and employment sector (public sector vs. private sector) were selected as potential confounders. The data were all obtained from The Longitudinal Database for Health Insurance and Labor Market Studies (LISA).

In addition to these factors, two indicators of negative physical work exposure, three health indicators, and two indicators of long-term sickness absence and disability pension were also used as confounders.

\subsubsection{Physical Working Conditions}

The following two items were chosen as indicators of heavy physical work and strenuous work postures. More detailed information on the items capturing physical work and on the response alternatives and coding can be found in previous publications by the research team [26].

- Heavy physical work-'Are you required to lift at least $15 \mathrm{~kg}$ at a time several times per day?'

- Strenuous work postures-'Do you bend or twist yourself in your work in the same way repeatedly for an hour, for several hours during the same day?'

The responses to the five-point response scale (every day, 1 day of 2, 1 day of 5, 1 day of 10, not at all) were dichotomized closest to the upper quartile to indicate the most adverse conditions. The responses were dichotomized into 'No' ( $\leq 1$ day of 5 ) and 'Yes' ( $\geq 1$ day of 2$)$, and 'Yes' (every day).

\subsubsection{Self-Rated symptoms}

Three items were chosen as indicators of health symptoms:

- "Have you experienced pain in your upper back or neck after working, during the past three months?"

- "Have you had trouble sleeping during the last three months?"

- "Have you felt tired and listless during the last three months?"

The responses to the five-point response scale on self-rated symptoms (every day, 1 day of 2, 1 day of 5, 1 day of 10, not at all) were dichotomized closest to the upper quartile to indicate the most adverse conditions. The responses were dichotomized into ' $\mathrm{No}^{\prime}$ ( $\leq 1$ day of 5$)$ and 'Yes' ( $\geq 1$ day of 2$)$, and 'Yes' (every day). The 'No' group was then used as the reference category in the analyses.

\subsubsection{Sickness Absence and Disability Pension}

Long-term sickness absence (LTSA) during the calendar year in which the individual was included in the SWES (spanning 2001-2013) was operationalized as the number of spells of the individuals medically certified sickness absence lasting 60 days or more, as recorded in the Swedish Social Insurance registers and obtained from the LISA database. The categories are 'No' ( $<60$ days) and 'Yes' ( $\geq 60$ days). 
All cases of granted full-time or part-time disability pension during the years following participation in the surveys (2002-2014) were included, regardless of the diagnostic category.

\subsection{Statistical Analyses}

The selected participants from the SWES surveys were consecutively added to the cohort (December 31, 2001-2013). The odds ratios (ORs) for presenteeism, with 95\% confidence intervals (CIs), were estimated using multiple logistic regression analysis. The statistical analyses were conducted in two steps. First, the ORs of the psychosocial variables and confounders of presenteeism were analyzed, one by one, adjusting for age (one-year intervals) and year of interview. Second, the associations between presenteeism and both psychosocial exposures and work ability were analyzed and stratified by sex and occupation into the categories of nursing professionals, care assistants, and all other occupations. Adjustment for two sets of confounders were made: Model 1, age at interview and year of interview and Model 2, age at interview and year of interview plus sociodemographic conditions, sector of employment, physical work conditions, health symptoms, sickness absence, and disability pension. All statistical analyses were conducted with SAS, version 9.4., statistical software (SAS Institute, Inc., Cary, North Carolina).

\section{Results}

Table 1 shows that care assistants went to work while ill significantly more often than nursing professionals and those in the all other occupations category according to the self-report analysis $(\mathrm{OR}=1.20,95 \% \mathrm{CI} 1.14-1.23)$. Furthermore, presenteeism was significantly related to being a woman, middle aged, less educated, employed in the public sector, and foreign born.

Table 1 also indicates a dose-response relationship between presenteeism and perceived work ability.

Table 2 contains information and findings about psychosocial working conditions and health indicators that may be related to presenteeism among the total study group. It shows highly significant ORs for three indicators of high psychosocial job demands; that is, "stressful—no time to think," "much work-miss lunch," and "far too much to do." Significant ORs were also noted for all indicators of low job control such as "determine work pace" and "influence." Similarly, little or no support from supervisors and from colleagues was associated with presenteeism. Furthermore, strenuous work postures and heavy lifting were also associated with presenteeism, as were negative health symptoms, LTSA ( $\geq 60$ days), and being granted a disability pension.

Table 1. Number of individuals, prevalence, and odds ratios (ORs) of presenteeism (two times or more) with $95 \%$ confidence intervals (CIs), related to sociodemographic variables (sex, age, education), employment sector, country of birth, occupation, and work ability, interviewed 2001-2013 ${ }^{\text {a }}$.

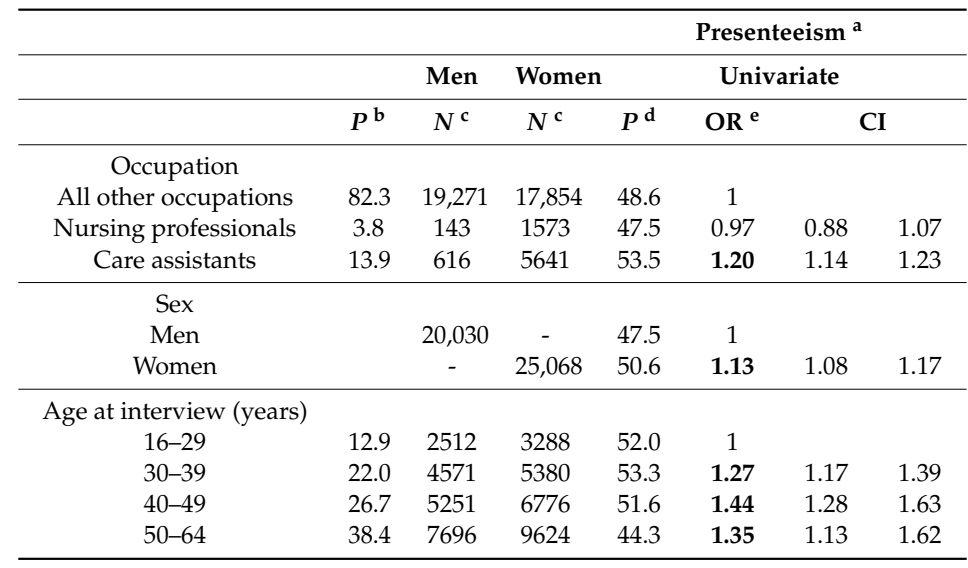


Table 1. Cont.

\begin{tabular}{|c|c|c|c|c|c|c|c|}
\hline & & & & \multicolumn{4}{|c|}{ Presenteeism $^{a}$} \\
\hline & \multicolumn{2}{|r|}{ Men } & \multicolumn{2}{|l|}{ Women } & \multicolumn{2}{|c|}{ Univariate } & \\
\hline & $P^{b}$ & $N^{\mathrm{c}}$ & $N^{\mathrm{c}}$ & $P^{\mathrm{d}}$ & $\mathrm{OR}^{\mathrm{e}}$ & \multicolumn{2}{|c|}{ CI } \\
\hline University or college & 42.4 & 7529 & 11,589 & 48.0 & 1 & & \\
\hline High school & 47.3 & 9885 & 11,445 & 50.2 & 1.08 & 1.04 & 1.13 \\
\hline Compulsory & 10.3 & 2602 & 2023 & 49.9 & 1.16 & 1.09 & 1.24 \\
\hline \multicolumn{8}{|l|}{ Employment sector } \\
\hline Private & 53.2 & 14,268 & 9507 & 48.1 & 1 & & \\
\hline Public & 46.8 & 5592 & 15,354 & 50.6 & 1.14 & 1.10 & 1.18 \\
\hline \multicolumn{8}{|l|}{ Country of birth } \\
\hline Sweden & 92.1 & 18,548 & 22,980 & 48.6 & 1 & & \\
\hline Other country & 7.9 & 1479 & 2088 & 56.4 & 1.38 & 1.29 & 1.48 \\
\hline \multicolumn{8}{|l|}{ Work ability ${ }^{\mathrm{f}}$} \\
\hline High, 10 points & 52.8 & 5979 & 7167 & 43.6 & 1 & & \\
\hline 9 points & 11.9 & 1516 & 1456 & 46.1 & 1.14 & 1.05 & 1.24 \\
\hline 8 points & 21.2 & 2578 & 2696 & 51.1 & 1.44 & 1.35 & 1.54 \\
\hline 7 points & 8.6 & 1055 & 1088 & 57.9 & 1.92 & 1.75 & 2.11 \\
\hline 6 points & 2.2 & 235 & 313 & 67.5 & 2.92 & 2.43 & 3.51 \\
\hline 5 points & 2.2 & 192 & 344 & 63.0 & 2.48 & 2.07 & 2.97 \\
\hline 4 points & 0.5 & 43 & 71 & 71.9 & 3.65 & 2.44 & 5.58 \\
\hline 3 points & 0.3 & 36 & 47 & 69.5 & 3.32 & 2.09 & 5.42 \\
\hline 2 points & 0.1 & 13 & 23 & 77.8 & 4.78 & 2.28 & 11.27 \\
\hline Low, 1 point & 0.2 & 22 & 28 & 75.0 & 3.94 & 2.11 & 7.93 \\
\hline
\end{tabular}

a The study group $(n=45,098) .{ }^{\mathrm{b}}$ Prevalence (P) of individuals (\%). ${ }^{\mathrm{c}}$ Number of individuals $(n) .{ }^{\mathrm{d}}$ Prevalence (P) of presenteeism, two times or more (\%). ${ }^{e}$ Odds ratio (OR) of presenteeism with $95 \%$ confidence interval (CI), adjusted for age (continuous variable) and year of interview. ${ }^{\mathrm{f}}$ Sub-sample 2007-2013 $n=24,902$. Bold $=$ statistically significant at the $p<0.05$ level

Table 2. Number of individuals, prevalence, and odds ratios (ORs) of presenteeism (two times or more) with $95 \%$ confidence intervals (CIs), related to psychosocial and physical work factors, health symptoms, long-term sickness absence, and disability pension, interviewed 2001-2013 a ${ }^{\text {. }}$

\begin{tabular}{|c|c|c|c|c|c|c|}
\hline & \multicolumn{6}{|c|}{ Presenteeism $^{a}$} \\
\hline & \multirow{2}{*}{$\begin{array}{l}\text { Men } \\
N^{\mathbf{b}}\end{array}$} & \multicolumn{2}{|c|}{ Women } & \multicolumn{3}{|c|}{ Univariate } \\
\hline & & $N^{b}$ & $P^{\mathrm{c}}$ & OR $^{d}$ & & $\mathbf{I}$ \\
\hline \multicolumn{7}{|l|}{ Job demands } \\
\hline Stressful—no time to think, Yes ( $\geq 3 / 4$ of working time) & 3402 & 6604 & 65 & 2.32 & 2.21 & 2.43 \\
\hline Attention/concentration, Yes ( $\geq 3 / 4$ of working time) & 7936 & 12,483 & 53 & 1.39 & 1.34 & 1.45 \\
\hline Much work - miss lunch etc., Yes ( $\geq 1$ day of 2$)$ & 4161 & 4770 & 64 & 2.16 & 2.06 & 2.27 \\
\hline Far too much to do, Yes (agree, partly agree) & 3019 & 5058 & 67 & 2.48 & 2.36 & 2.62 \\
\hline \multicolumn{7}{|l|}{ Job control } \\
\hline Determine work pace, No ( $\leq 1 / 10$ of working time) & 3390 & 7400 & 58 & 1.59 & 1.52 & 1.66 \\
\hline Determine working duties, No (no, not at all) & 2306 & 5355 & 53 & 1.22 & 1.16 & 1.28 \\
\hline Participate in decisions, No ( $\leq$ mostly not $)$ & 4536 & 6821 & 52 & 1.16 & 1.11 & 1.21 \\
\hline Influence, No (disagree, partly disagree) & 4811 & 6555 & 58 & 1.58 & 1.52 & 1.65 \\
\hline \multicolumn{7}{|l|}{ Job support } \\
\hline Support from supervisors, Mostly not-never & 7472 & 7753 & 58 & 1.75 & 1.68 & 1.82 \\
\hline Support from colleagues, Mostly not-never & 3964 & 2914 & 57 & 1.54 & 1.46 & 1.62 \\
\hline \multicolumn{7}{|l|}{ Physical work } \\
\hline Strenuous work postures, Yes (every day) & 3889 & 5992 & 59 & 1.63 & 1.56 & 1.71 \\
\hline Heavy lifting, Yes ( $\geq 1$ day out of 2$)$ & 5312 & 4232 & 60 & 1.73 & 1.65 & 1.81 \\
\hline \multicolumn{7}{|l|}{ Health symptoms } \\
\hline Upper back or neck pain, $\geq 1$ day of 2 & 3441 & 7383 & 67 & 2.67 & 2.55 & 2.79 \\
\hline Tired and listless, $\geq 1$ day of 2 & 3187 & 6082 & 72 & 3.33 & 3.17 & 3.51 \\
\hline Sleeping troubles, $\geq 1$ day of 5 & 3705 & 5871 & 68 & 2.86 & 2.73 & 3.00 \\
\hline Long-term sickness absence, Yes ( $\geq 60$ days) & 492 & 1268 & 67 & 2.31 & 2.09 & 2.56 \\
\hline Disability pension after interview, Yes & 287 & 705 & 67 & 2.33 & 2.04 & 2.68 \\
\hline
\end{tabular}

a The study group $(n=45,098) .{ }^{\mathrm{b}}$ Number of individuals $(n) .{ }^{\mathrm{c}}$ Prevalence $(\mathrm{P})$ of presenteeism, two times or more $(\%) .{ }^{d}$ Odds ratio (OR) of presenteeism with $95 \%$ confidence interval (CI), adjusted for age (continuous variable) and year of interview. Bold $=$ statistically significant at the $p<0.05$ level. 
95\% CI 1.34-1.71). Also, a lack of support from supervisors, but not from colleagues, had a significant association with presenteeism among both nurses and care assistants.

Table 4. Associations between presenteeism and sex, psychosocial variables, and work ability, stratified by occupation ${ }^{\text {a }}$. Number of cases and odds ratios (ORs) with $95 \%$ confidence intervals (CIs) are presented.

\begin{tabular}{|c|c|c|c|c|c|c|c|c|c|c|c|c|c|c|c|}
\hline & \multirow[b]{3}{*}{$N^{\mathrm{b}}$} & \multicolumn{14}{|c|}{ Presenteeism } \\
\hline & & \multicolumn{4}{|c|}{ All Other $n=37,125$} & \multicolumn{5}{|c|}{ Nursing Professionals $n=1716$} & \multicolumn{5}{|c|}{ Care Assistants $n=6257$} \\
\hline & & $\mathrm{OR}^{\mathrm{c}}$ & OR $^{d}$ & CI & CI & $N^{b}$ & OR $^{c}$ & OR $^{d}$ & CI & CI & $\mathbf{N}^{\mathbf{b}}$ & $\mathrm{OR}^{\mathrm{c}}$ & OR $^{d}$ & CI & CI \\
\hline \multicolumn{16}{|l|}{ Sex } \\
\hline Man & 10,085 & 1 & 1 & & & 72 & 1 & 1 & & & 297 & 1 & 1 & & \\
\hline Women & 8889 & 1.10 & 0.96 & 0.91 & 1.00 & 823 & 0.98 & 0.85 & 0.58 & 1.24 & 2591 & 1.11 & 0.87 & 0.73 & 1.05 \\
\hline \multicolumn{16}{|l|}{ Job Demands } \\
\hline $\begin{array}{l}\text { Stressful-no time to think } \\
\text { Yes ( } \geq 3 / 4 \text { of working time) }\end{array}$ & 2875 & 2.33 & 1.63 & 1.54 & 1.73 & 202 & 2.32 & 1.70 & 1.34 & 2.14 & 454 & 2.28 & 1.58 & 1.37 & 1.83 \\
\hline $\begin{array}{l}\text { Attention/concentration, } \\
\text { Yes ( } \geq 3 / 4 \text { of time) }\end{array}$ & 15,885 & 1.39 & 1.15 & 1.09 & 1.20 & 481 & 1.51 & 1.28 & 1.04 & 1.59 & 1485 & 1.34 & 1.13 & 1.01 & 1.26 \\
\hline $\begin{array}{c}\text { Much work-miss lunch etc. } \\
\text { Yes }(\geq 1 \text { day of } 2)\end{array}$ & 7670 & 2.19 & 1.73 & 1.63 & 1.82 & 182 & 2.15 & 1.51 & 1.19 & 1.93 & 213 & 2.39 & 1.54 & 1.28 & 1.86 \\
\hline $\begin{array}{c}\text { Far too much to do } \\
\text { Yes (agree, partly agree) }\end{array}$ & 6643 & 2.46 & 1.78 & 1.67 & 1.89 & 109 & 2.86 & 1.97 & 1.50 & 2.61 & 300 & 2.58 & 1.72 & 1.46 & 2.03 \\
\hline \multicolumn{16}{|l|}{ Job Control } \\
\hline $\begin{array}{l}\text { Determine work pace } \\
\text { No ( } \leq 1 / 10 \text { of time) }\end{array}$ & 7649 & 1.62 & 1.27 & 1.20 & 1.34 & 329 & 1.29 & 1.14 & 0.92 & 1.41 & 986 & 1.46 & 1.21 & 1.08 & 1.36 \\
\hline $\begin{array}{l}\text { Determine working duties } \\
\text { No (no, not at all) }\end{array}$ & 4906 & 1.21 & 0.97 & 0.91 & 1.04 & 298 & 1.07 & 0.93 & 0.75 & 1.17 & 938 & 1.17 & 1.07 & 0.95 & 1.21 \\
\hline $\begin{array}{l}\text { Participate in decisions, } \\
\text { No }(\leq \text { mostly not })\end{array}$ & 8800 & 1.16 & 0.98 & 0.93 & 1.03 & 264 & 1.16 & 1.07 & 0.85 & 1.34 & 878 & 1.10 & 1.01 & 0.90 & 1.14 \\
\hline $\begin{array}{c}\text { Influence, } \\
\text { No (disagree, partly disagree) }\end{array}$ & 8997 & 1.53 & 1.25 & 1.19 & 1.32 & 211 & 1.92 & 1.61 & 1.28 & 2.02 & 664 & 1.76 & 1.51 & 1.34 & 1.71 \\
\hline \multicolumn{16}{|l|}{ Support from supervisors } \\
\hline $\begin{array}{l}\text { Mostly not-never } \\
\text { Support from colleagues }\end{array}$ & 12538 & 1.76 & 1.42 & 1.36 & 1.49 & 257 & 1.76 & 1.40 & 1.12 & 1.75 & 749 & 1.72 & 1.44 & 1.28 & 1.63 \\
\hline Mostly not-never & 6196 & 1.57 & 1.33 & 1.25 & 1.41 & 51 & 1.87 & 1.37 & 0.91 & 2.08 & 201 & 1.40 & 1.17 & 0.94 & 1.45 \\
\hline \multicolumn{16}{|l|}{ Work ability ${ }^{\mathrm{e}}$} \\
\hline High, 10 points & 4842 & 1 & 1 & & & 216 & 1 & 1 & & & 653 & 1 & 1 & & \\
\hline 9 points & 1174 & 1.12 & 1.06 & 0.97 & 1.16 & 48 & 1.03 & 0.93 & 0.59 & 1.45 & 139 & 1.43 & 1.36 & 1.03 & 1.81 \\
\hline 8 points & 2232 & 1.42 & 1.23 & 1.14 & 1.33 & 67 & 1.15 & 0.92 & 0.61 & 1.38 & 385 & 1.63 & 1.44 & 1.18 & 1.76 \\
\hline 7 points & 1010 & 1.89 & 1.43 & 1.28 & 1.60 & 37 & 1.75 & 1.12 & 0.63 & 1.98 & 190 & 2.10 & 1.51 & 1.14 & 2.00 \\
\hline Low, $1-6$ points & 725 & 2.74 & 1.68 & 1.45 & 1.94 & 28 & 6.43 & 3.82 & 1.57 & 10.77 & 153 & 3.21 & 1.97 & 1.40 & 2.79 \\
\hline
\end{tabular}

${ }^{\text {a }}$ All individuals in the study group $(n=45,098) .{ }^{\mathrm{b}}$ Number of cases with presenteeism, two times or more. ${ }^{\mathrm{c}}$ Model 1; Odds ratio (OR) of presenteeism with $95 \%$ confidence interval (CI), adjusted for age (continuous variable) and year of interview. ${ }^{\mathrm{d}}$ Model 2; Odds ratio (OR) of presenteeism with $95 \%$ confidence interval (CI), adjusted for education, sector of employment, country of birth, physical work (2 variables), three health symptoms, long-term sickness absence, disability pension, age (continuous variable), and year of interview. ${ }^{\mathrm{e}}$ Sub-sample 2007-2013, $n=24,902$. Bold $=$ statistically significant at the $p<0.05$ level.

In the all other occupation group, both a lack of support from supervisors and from colleagues increased the OR estimates of presenteeism significantly, but among nursing professionals and care assistants the increase in support from colleagues was not significant when adjustment for confounders was introduced. In all three groups, presenteeism was significantly related to low work ability, with particularly high ORs of presenteeism among nursing professionals reporting low work ability $(\mathrm{OR}=3.82,95 \% \mathrm{CI} 1.57-10.77)$. Among care assistants, the associations between presenteeism and work ability were less pronounced, albeit significant, and those reporting the lowest level of work ability had an OR of 1.97 (95\% CI 1.40-1.79). There were no significant differences between women and men for any of the three occupational groups when the selected confounders were included in the analyses.

\section{Discussion}

The present study examined the relationships between presenteeism and both psychosocial working conditions and perceived work ability. The focus was on sex differences and the two occupational groups of nursing professionals and care assistants. 
The study showed that presenteeism was most common among care assistants and that its prevalence among nursing professionals did not deviate from that among the all other occupations group. The high prevalence of presenteeism found among care assistants is in line with findings from studies from other countries [3-6,11,20,27-29]. Unlike the present study, other studies have found that nursing professionals have higher levels of presenteeism than other occupations $[7,9,16,17,30]$.

An interesting sex-related finding was that the higher levels of presenteeism found among women in the univariate analyses were no longer found for any of the three groups after controlling for confounders in the stratified analyses. Previous studies have reached contradictory conclusions concerning the differences between women and men, with some showing no differences in the prevalence of presenteeism between the sexes $[5,13]$ and others reporting higher prevalence among women $[2,3,11,12]$. The reason why the gender differences in presenteeism rates disappeared after confounder control is that factors such as education, exposure to heavy physical work and health symptoms are included among the confounders and that there are sex differences in the prevalence of these factors.

The fact that younger nurses and care assistants had lower levels of presenteeism than their older counterparts may be related to the fact that their employment security is weaker, but it may also be related to their lower income security or lower level of loyalty towards patients or employees.

Our results showing associations between presenteeism and psychosocial working conditions, particularly high job demands and low job support, are supported by a large number of previous studies of healthcare and social care employees $[2,4,7,9-13,20]$. It should be noted, however, that the prevalence of presenteeism has been rather stable over time among health and care employees as well as among the general working population (Statistics Sweden, Swedish Work Environment Survey, scb.se) [22], despite a marked increase in demanding psychosocial conditions in the last few decades in Sweden [26]. This can indicate that there may also be compensating factors at work or other factors that affect the individuals' choice of presenteeism that have not been included in the present study. Increased employment insecurity may, for example, increase presenteeism, while increased sickness absence may mean lower presenteeism. Also, the finding of presenteeism being related to previous, present, and future health problems has also been reported in a number of studies $[2,3,9,11,12,14,20,31-33]$. A couple of studies have shown that intention to leave one's occupation and risk of disability pension are higher among employees in health and care occupations where presenteeism is prevalent $[25,34]$.

The study found strong associations between presenteeism and low work ability and it was remarkable that the risk of presenteeism among those who reported the lowest degree of work ability was almost fourfold higher among nurses and twofold higher among care assistants. These associations remained even after controlling for ill-health symptoms. Associations between presenteeism and reduced work ability is in line with studies from other countries, although different definitions of work ability and productivity have been applied in the studies $[1,7,8,13,15,16,21,30,35,36]$. One study that focused on the relationship between reduced work ability and productivity loss argued that perceived work ability is a robust indicator for assessing productivity loss [21]. Thus, the relatively high level of presenteeism in healthcare occupations and the fact that a large number of employees who engage in presenteeism report very low work ability indicates that many employees in this sector are not working to the best of their abilities. Additionally, presenteeism has been shown to increase the risk of spreading infectious diseases [19], a potentially detrimental hazard in health and care settings [17,18].

\section{Strengths and Limitations}

In the current study, the number of interviews was large and based on representative samples from the working population, and the response rates to the questionnaires were satisfactory. Since poor health is the root of sickness presenteeism, individuals' health symptoms, sickness absence and disability pension status were controlled for. To the best of our knowledge, no other Swedish studies have investigated presenteeism in relation to work ability among care workers. The present study has some limitations. One is that it was not possible to draw causal conclusions because of the cross-sectional 
design in which working conditions and self-reported health symptoms were assessed at the same point in time as presenteeism. Still, presenteeism was measured through a retrospective question referring to the previous year, while the other factors concerned the present situation. Although the associations between reduced health and presenteeism and between reduced health and low work ability may seem trivial, the causal mechanisms are not well known. One reason for this is the lack of information on how health conditions are assessed by the individuals when they decide to go to work ill $[1,5,12]$.

\section{Conclusions}

The study indicated that presenteeism among healthcare and care employees, as well as among other occupations, was associated with high job demands and lack of supervisor job support. There were also extremely strong associations between presenteeism and low work ability. This may affect productivity and safety in healthcare organizations as well as the present and future health (and sickness absence) of its employees. It may also be a health risk for the patients. In order to reduce presenteeism and low work ability, and thus the problems they lead to, efforts should be made to improve psychosocial working environments. Reduction in job demands and improvements in supervisory support, as well as educational and psychological measures to give nurses and care assistants better strategies to meet stress at work, are essential both for the individuals and for the health and care organizations.

Author Contributions: Conceptualization, K.G., S.M., C.L., G.B., E.A. and M.H.; Data curation, C.L.; Formal analysis, K.G.; Funding acquisition, K.G., C.L., G.B. and M.H.; Investigation, K.G., S.M., C.L., G.B., E.A. and M.H.; Methodology, K.G., S.M., C.L., G.B., E.A. and M.H.; Project administration, K.G., C.L., G.B. and M.H.; Resources, K.G. and C.L.; Software, K.G.; Supervision, K.G.; Validation, K.G., S.M., C.L., G.B., E.A. and M.H.; Visualization, K.G., S.M., C.L., G.B., E.A. and M.H.; Writing—original draft, K.G.; Writing—review \& editing, S.M., C.L., G.B., E.A. and M.H. All authors have read and agreed to the published version of the manuscript.

Funding: Working Life and Social Research, Sweden: 2015-00549

Acknowledgments: The authors would like to thank Viktor Persson, whose initial computer work yielded the basic data of the study. We are also grateful to David Speeckaert for his language revision of the text. The study was supported and financed by the Swedish Council for Working Life and Social Research, Sweden (Dnr: 2015-00549) and AFA Insurance, owned by the major labor market organizations in Sweden, Dnr: 170100 and Dnr: 170114. The data collection was financed by the Swedish Research Council (VR) (grant numbers 2009-06192, 2013-01645, and 2013-01646). The funders had no role in study design, data collection and analysis, decision to publish, or preparation of the manuscript.

Conflicts of Interest: The authors have no conflicts of interest to declare.

\section{References}

1. Johns, G. Presenteeism in the workplace: A review and research agenda. J. Organ. Behav. 2010, 31, 519-542. [CrossRef]

2. Miraglia, M.; Johns, G. Going to work ill: A meta-analysis of the correlates of presenteeism and a dual-Path model. J. Occup. Health Psychol. 2016, 21, 261-283. [CrossRef] [PubMed]

3. Aronsson, G.; Gustafsson, K.; Dallner, M. Sick but yet at work. An empirical study of sickness presenteeism. J. Epidemiol. Community Health 2000, 54, 502-509. [CrossRef] [PubMed]

4. Elstad, J.I.; Vabo, M. Job stress, sickness absence and sickness presenteeism in Nordic elderly care. Scand J. Public Health 2008, 36, 467-474. [CrossRef]

5. Hansen, C.D.; Andersen, J.H. Going ill to work-What personal circumstances, attitudes and work-Related factors are associated with sickness presenteeism? Soc. Sci. Med. 2008, 67, 956-964. [CrossRef]

6. Dhaini, S.; Zuniga, F.; Ausserhofer, D.; Simon, M.; Kunz, R.; De Geest, S.; Schwendimann, R. Absenteeism and Presenteeism among Care Workers in Swiss Nursing Homes and Their Association with Psychosocial Work Environment: A Multi-Site Cross-Sectional Study. Gerontology 2015, 62, 386-395. [CrossRef]

7. Umann, J.; Guido Lde, A.; Grazziano Eda, S. Presenteeism in hospital nurses. Rev. Lat.-Am. de Enferm. 2012, 20, 159-166. [CrossRef] 
8. Warren, C.L.; White-Means, S.I.; Wicks, M.N.; Chang, C.F.; Gourley, D.; Rice, M. Cost burden of the presenteeism health outcome: Diverse workforce of nurses and pharmacists. J. Occup. Environ. Med. 2011, 53, 90-99. [CrossRef]

9. Brborovic, H.; Daka, Q.; Dakaj, K.; Brborovic, O. Antecedents and associations of sickness presenteeism and sickness absenteeism in nurses: A systematic review. Int. J. Nurs. Pract. 2017, 23. [CrossRef]

10. Demerouti, E.; Le Blanc, P.M.; Bakker, A.B.; Schaufeli, W.B.; Hox, J. Present but sick: A three-Wave study on job demands, presenteeism and burnout. Career Dev. Int. 2009, 14, 50-68. [CrossRef]

11. Allemann, A.; Siebenhuner, K.; Hammig, O. Predictors of Presenteeism among Hospital Employees: A Cross-Sectional Questionnaire-Based Study in Switzerland. J. Occup. Environ. Med. 2019, 61, 1004-1010. [CrossRef] [PubMed]

12. Gosselin, E.; Lemyre, L.; Corneil, W. Presenteeism and absenteeism: Differentiated understanding of related phenomena. J. Occup. Health Psychol. 2013, 18, 75-86. [CrossRef] [PubMed]

13. Johns, G. Attendance dynamics at work: The antecedents and correlates of presenteeism, absenteeism, and productivity loss. J. Occup. Health Psychol. 2011, 16, 483-500. [CrossRef] [PubMed]

14. Bernal, D.; Campos-Serna, J.; Tobias, A.; Vargas-Prada, S.; Benavides, F.G.; Serra, C. Work-Related psychosocial risk factors and musculoskeletal disorders in hospital nurses and nursing aides: A systematic review and meta-Analysis. Int. J. Nurs. Stud. 2015, 52, 635-648. [CrossRef] [PubMed]

15. Kinman, G. Sickness presenteeism at work: Prevalence, costs and management. Br. Med Bull. 2019, 129, 69-78. [CrossRef]

16. Letvak, S.A.; Ruhm, C.J.; Gupta, S.N. Nurses' presenteeism and its effects on self-Reported quality of care and costs. Am. J. Nurs. 2012, 112, 30-38. [CrossRef]

17. Aysun, K.; Bayram, S. Determining the level and cost of sickness presenteeism among hospital staff in Turkey. Int. J. Occup. Saf. Ergon. 2017, 23, 501-509. [CrossRef]

18. Widera, E.; Chang, A.; Chen, H.L. Presenteeism: A public health hazard. J. Gen. Intern. Med. 2010, 25, 1244-1247. [CrossRef]

19. Webster, R.K.; Liu, R.; Karimullina, K.; Hall, I.; Amlot, R.; Rubin, G.J. A systematic review of infectious illness Presenteeism: Prevalence, reasons and risk factors. BMC Public Health 2019, 19, 799. [CrossRef]

20. Rantanen, I.; Tuominen, R. Relative magnitude of presenteeism and absenteeism and work-Related factors affecting them among health care professionals. Int. Arch. Occup. Environ. Health 2011, 84, 225-230. [CrossRef]

21. Vanni, K.; Virtanen, P.; Luukkaala, T.; Nygard, C.H. Relationship between perceived work ability and productivity loss. Int. J. Occup. Saf. Ergon. 2012, 18, 299-309. [CrossRef] [PubMed]

22. Arbetsmiljöverket. Arbetsmiljön 2015 [The Work Environment 2015]; Arbetsmiljöverket: Stockholm, Sweden, 2016.

23. Magnusson Hanson, L.L.; Theorell, T.; Oxenstierna, G.; Hyde, M.; Westerlund, H. Demand, control and social climate as predictors of emotional exhaustion symptoms in working Swedish men and women. Scand J. Public Health 2008, 36, 737-743. [CrossRef] [PubMed]

24. Karasek, R.A.; Theorell, T. Healthy Work: Stress, Productivity and the Reconstuctions of Work Life; Basic Books: New York, NY, USA, 1990.

25. Leineweber, C.; Marklund, S.; Aronsson, G.; Gustafsson, K. Work-Related psychosocial risk factors and risk of disability pension among employees in health and personal care: A prospective cohort study. Int. J. Nurs. Stud. 2019, 93, 12-20. [CrossRef] [PubMed]

26. Marklund, S.; Gustafsson, K.; Leineweber, C.; Aronsson, G.; Helgesson, M. Working conditions and compensated sickness absence among nurses and care assistants in Sweden during two decades-A cross-sectional biennial survey study. BMJ Open 2019, 9. [CrossRef] [PubMed]

27. Dhaini, S.R.; Zuniga, F.; Ausserhofer, D.; Simon, M.; Kunz, R.; De Geest, S.; Schwendimann, R. Care workers health in Swiss nursing homes and its association with psychosocial work environment: A cross-sectional study. Int. J. Nurs. Stud. 2016, 53, 105-115. [CrossRef]

28. Gustafsson, K.; Bergstrom, G.; Marklund, S.; Aboagye, E.; Leineweber, C. Presenteeism as a predictor of disability pension: A prospective study among nursing professionals and care assistants in Sweden. J. Occup. Health 2019, 61, 453-463. [CrossRef] 
29. Dhaini, S.R.; Zuniga, F.; Ausserhofer, D.; Simon, M.; Kunz, R.; De Geest, S.; Schwendimann, R. Are nursing home care workers' health and presenteeism associated with implicit rationing of care? A cross-Sectional multi-site study. Geriatr. Nurs. 2017, 38, 33-38. [CrossRef]

30. Pilette, P.C. Presenteeism in nursing: A clear and present danger to productivity. J. Nurs. Adm. 2005, 35, 300-303. [CrossRef]

31. Bergstrom, G.; Bodin, L.; Hagberg, J.; Aronsson, G.; Josephson, M. Sickness presenteeism today, sickness absenteeism tomorrow? A prospective study on sickness presenteeism and future sickness absenteeism. J. Occup. Environ. Med. 2009, 51, 629-638. [CrossRef]

32. Gustafsson, K.; Marklund, S. Consequences of sickness presence and sickness absence on health and work ability: A Swedish prospective cohort study. Int. J. Occup. Med. Environ. Health 2011, 24, 153-165. [CrossRef]

33. Skagen, K.; Collins, A.M. The consequences of sickness presenteeism on health and wellbeing over time: A systematic review. Soc. Sci. Med. 2016, 161, 169-177. [CrossRef] [PubMed]

34. Li, J.; Galatsch, M.; Siegrist, J.; Muller, B.H.; Hasselhorn, H.M.; European, N.S.G. Reward frustration at work and intention to leave the nursing profession-Prospective results from the European longitudinal NEXT study. Int. J. Nurs. Stud. 2011, 48, 628-635. [CrossRef] [PubMed]

35. Aboagye, E.; Bjorklund, C.; Gustafsson, K.; Hagberg, J.; Aronsson, G.; Marklund, S.; Leineweber, C.; Bergstrom, G. Exhaustion and Impaired Work Performance in the Workplace: Associations With Presenteeism and Absenteeism. J. Occup. Environ. Med. 2020. [CrossRef] [PubMed]

36. Li, Y.; Zhang, J.; Wang, S.; Guo, S. The Effect of Presenteeism on Productivity Loss in Nurses: The Mediation of Health and the Moderation of General Self-Efficacy. Front. Psychol. 2019, 10, 1745. [CrossRef] [PubMed]

(C) 2020 by the authors. Licensee MDPI, Basel, Switzerland. This article is an open access article distributed under the terms and conditions of the Creative Commons Attribution (CC BY) license (http://creativecommons.org/licenses/by/4.0/). 